\title{
Fire and
}

\section{brimstone}

\section{Jonathan Fink}

The Lyman Hawaiian Earthquake Diary, 1833-1917. By M. Wyss, R. Y. Koyanagi and D. C. Cox. US Geological Survey Bulletin 2027, USGS: 1992. Pp. 34. $\$ 2.75$ (pbk).

Hawai i Volcano Watch: A Pictorial History, 1779-1991. By T. L. Wright, T. J. Takahashi and J. D. Griggs. University of Hawaii Press: 1992. Pp. 162. \$42 (hbk), \$24.95 (pbk).

FEW things instil the fear of God like a volcanic eruption. That may be why missionaries flock to places where volcanoes dominate the landscape, such as Latin America and the Pacific Islands. Although many of these religious salespeople rely on the fear of natural catastrophes to supply them with customers, others strive to understand their natural surroundings. So it was with early Christian settlers in the Hawaiian islands, several of whom used soul-saving as an excuse to explore the local volcanoes. Two recent publications illustrate how accurately their observations presaged those of modern scientists, and even provided a unique dataset still useful today for predicting future eruptive activity.

Sarah Lyman, a missionary wife transplanted from Vermont, would seem to be an unlikely candidate for chief Hawaiian seismologist. Yet a diary she and her daughter-in-law kept between 1833 and 1917 now represents the only continuous record of Hawaiian earthquake activity in the nineteenth century. The diary has recently been published with a recalibration and interpretation as The Lyman Hawaiian Earthquake Diary, 1833-1917. This valuable compilation allows the modern Hawaiian seismic re-

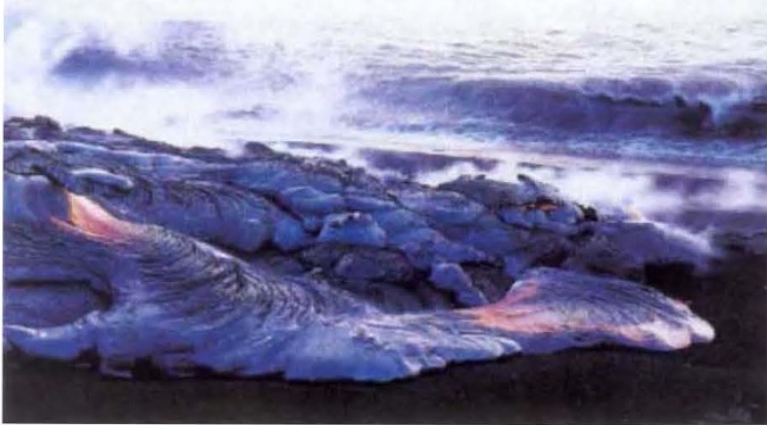

Lava from a Kllauea eruption covers the beach east of Kupapau Point. (USGS photo by J. D. Griggs, 1988.)

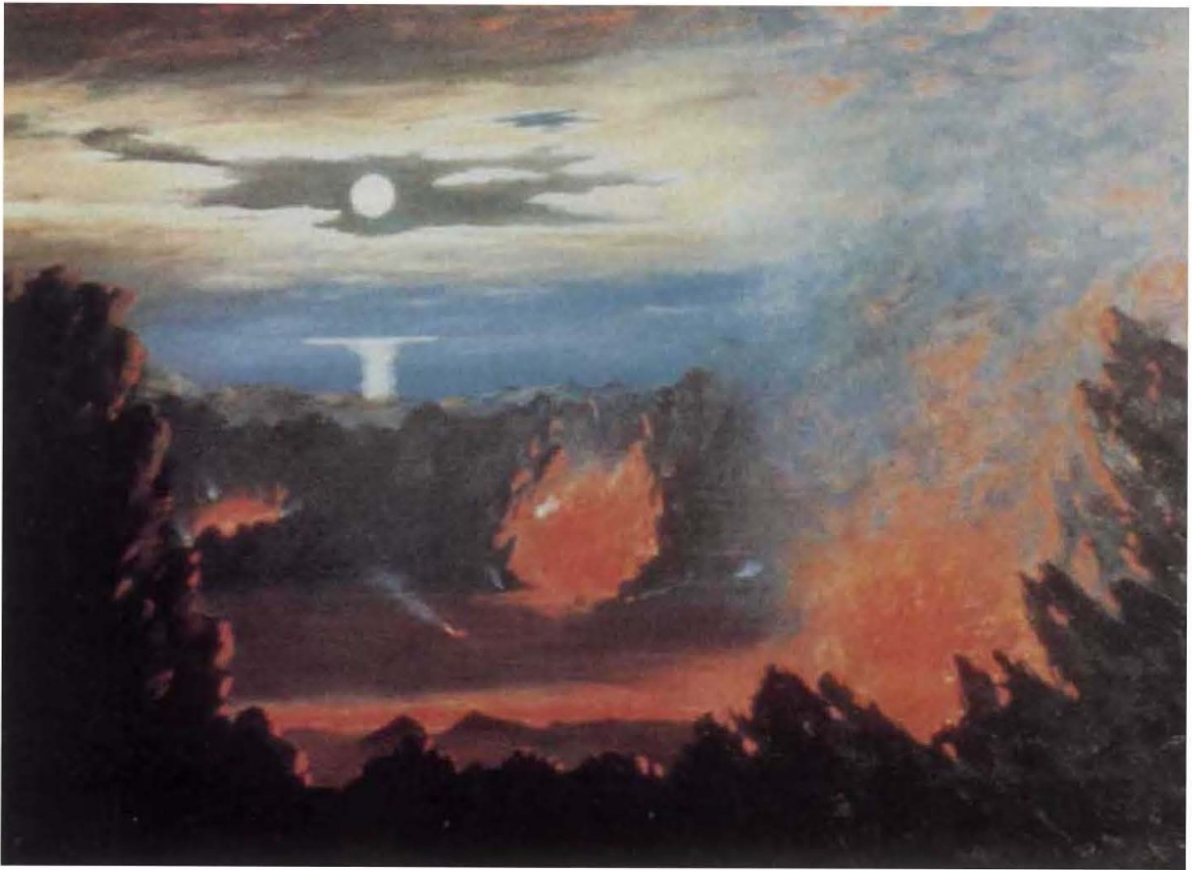

Kllauea by moonlight, painting by E. Bailey (1901).

cord to be extended back to before the giant Kau earthquake of 1868 , the largest ever documented for the islands.

Wyss and his colleagues convert the Lymans' descriptive entries (for example, "1875 Jan 29th: A smart shake at $12: 15 \mathrm{M}$. preceeded some 12 seconds by a sudden bump \& followed by several seconds of trembling") to the Modified Mercalli Intensity Scale, which relates earthquake shaking to its effect on manmade structures. They then plot the way in which the number of intense Hawaiian earthquakes has varied from 1832 to the present. The data reveal a relatively quiet period before the major 1868 earthquake, a very active interval from 1868 to the start of modern recordkeeping in 1915, and an intermediate level after that. Clearly, the 1868 event caused changes in the volcano's structure that were felt for nearly five decades. Recognizing such longterm trends is an essential part of any volcanic forecast because they help define cyclic patterns not evident in short-term records.

The Lymans were part of an inquisitive group of nineteenth century Hawaiian missionaries, explorers and scientists who were lured to eruptions by the same fascination that draws modern tourists, journalists and geologists. Hawaii Volcano Watch is a delightful new book that incorporates the impressions of these early observers into a vividly illus- trated chronicle of Hawaiian volcanology, from the early Polynesians' worship of the volcano goddess Pele to contemporary monitoring using lasers, satellites and supercomputers.

Historical perspective, enhanced by an outstanding collection of paintings, sketches, maps and photographs, two examples of which are shown here, offers lessons for scientists and Hawaiian residents alike. Geologists may become less smug on learning that many of their most important 'recent' findings, such as the age progression of the island chain or the role of lava tubes in producing very long flows, were actually proposed more than a century ago. Retired people from the mainland drawn to vacation homes on Kilauea's slopes may hesitate when reminded that more than 90 per cent of the volcano's land surface has been covered by lava since the arrival of the first Hawaiians some 1,500 years ago. And developers building palatial resorts along the beaches of Hawaii's Kona coast and the island of Maui, out of view of Kilauea's frequent ourtbursts, won't want to publicize the fact that lava flows have threatened these areas within the geologically recent past 200 years.

Geology is based on the principle that the present is the key to understanding the past. By highlighting the prescient contributions of early volcano watchers, these two books turn the maxim around: for Hawaiian volcanology, the past has often been the key to the present.

Jonathan Fink is in the Division of Earth Sciences, National Science Foundation, $1800 \mathrm{G}$ Street NW, Washington DC 20550, USA. 